\section{Sources of Resistance to Race 2WF Powdery Mildew in U.S. Watermelon Plant Introductions}

\author{
Haiying Zhang, Shaogui Guo, Guoyi Gong, and Yi Ren \\ National Engineering Research Center for Vegetables, Beijing Academy of \\ Agricultural and Forestry Sciences, No. 9 Shuguanghuayuan Road, Haidian \\ District, Beijing, 100097, China
}

Angela R. Davis
Wes Watkins Agricultural Research Laboratory, U.S. Department of Agriculture,
Agriculture Research Service, P.O. Box 159, East Highway 3, Lane, OK 74555

Yong $\mathrm{Xu}^{1}$

National Engineering Research Center for Vegetables, Beijing Academy of Agricultural and Forestry Sciences, No. 9 Shuguanghuayuan Road, Haidian District, Beijing, 100097, China

Additional index words. Citrullus lanatus, Podosphaera xanthii, host plant resistance, breeding

Abstract. Powdery mildew of cucurbits, incited by Podosphaera xanthii (Castagne) Braun
$\&$ Shishkoff (syn. Sphaerotheca fuliginea auct. p.p.), is an economically important foliar
disease. which is now common in watermelon [Citrullus lanatus (Thunb.) Mastum. \&
Nakai]. This disease occurs in all watermelon-growing areas and can reduce yields by up
to $30 \%$. Finding and breeding for resistance to this disease is important to reduce
dependence on fungicides and to use in combination with fungicides to limit the spread of
fungicide-resistant $P$. xanthii. This is the first English report that race 2 WF of $P$. xanthii
can infect watermelon. It is the prevalent race of watermelon powdery mildew in Beijing.

Watermelon PIs resistant to this disease may be valuable in watermelon breeding programs. We evaluated 2100 PI S1 lines, representing self-pollinated progeny of 820 accessions from the U.S. Citrullus sp. PI collection, for resistance to race $2 \mathrm{WF}$ powdery mildew. The accessions represent three species, C. lanatus var. lanatus (766), C. lanatus var. citroides (L. H. Bailey) Mansf. (53), and C. colocynthis (L.) Schrad. (1). Thirty lines demonstrated resistance; the most notable resistance was observed in 11 PI lines, PI 482246, PI 482283, PI 500307, PI 482324, PI 482308, PI 482322, PI 482321, PI 482276, PI 482319, PI 482335, and PI 482350. The majority of the resistant accessions were

Received for publication 22 June 2011. Accepted for publication 8 July 2011.

The research was supported by Beijing Municipal Science \& Technology Commission, China (Z09090501040902, D08070500690803, and 5100001), The Ministry of Science and Technology of the People's Republic of China (2009BADB8B02, 2010DFB33740, 30972015, and 2010AA10A107), and The Ministry of Agriculture of the People's Republic of China (CARS-26).

We thank Dr. Kai Shu Ling at the USDA-ARS, U.S. Vegetable Laboratory, for his critical review of the manuscript.

USDA is an equal opportunity provider and employer.

${ }^{1}$ To whom reprint requests should be addressed; e-mailxuyong@nercv.org. collected in Africa and include 12 C. lanatus var. lanatus and 18 C. lanatus var. citroides.

Watermelon production is increasing throughout China as a result of the crop's economic value; the Food and Agriculture Organization of the United Nations reports a total production for 2008 of 67.2 million MT (FAO of the United Nations, 2011). Over the past 20 years, powdery mildew has become a yield-limiting disease for this crop in China and other parts of the world (Davis et al., 2001; Feng, 1996; McGrath, 2001). This disease diminishes yields through decreased fruit size and fewer fruit per plant (McGrath and Thomas, 1996). Although the disease can often be managed with fungicides, adequate disease control frequently requires systemic fungicides because application to leaf undersides is difficult. The occurrence of powdery mildew populations resistant to fungicides is increasing (McGrath, 2001; McGrath and Thomas, 1996; for a review, see Lebeda et al., 2010). Resistant watermelon cultivars are important for slowing the spread of fungicideresistant Podosphaera xanthii and will offer growers options for disease control.

P. xanthii and Golovinomyces cichoracearum (D.C.) V.P. Heluta (formerly Erysiphe cichoracearum D.C.) are the predominant fungi that cause powdery mildew in cucurbits. These organisms differ in virulence against cucurbit species and in their sensitivity to fungicides (Lebeda et al., 2008). Presently, there are at least seven pathogenically distinct races of $P$. xanthii and these are differentiated using 10 melon (Cucumis melo L.) differentials (Hosoya et al., 1999; McCreight et al., 1987; Pitrat et al., 1998). Recent work by McCreight (2006) showed that there may be as many as 28 races of $P$. xanthii on melon that include eight variants of race 1 and six variants of race 2 . Currently, races $1 \mathrm{~W}$ and $2 \mathrm{~W}$ of $P$. xanthii have been reported on watermelon in the United States and G. cichoracearum was reported to affect watermelon in the Czech Republic (Davis et al., 2006, 2007; Kristková and Lebeda, 2000; Shishkoff and McGrath, 2001; Tetteh et al., 2010; Thomas, et al., 2005). Wang et al. (2006) determined the predominant cucurbit powdery mildew race in Beijing was race 2 Watermelon France (race $2 \mathrm{WF}$ ) and demonstrated this race infected watermelon.

Davis et al. (2006) released watermelon selection PI 525088-PMR resistant to race $1 \mathrm{~W} P$. xanthii and later published the results of their screening 1573 PI accessions for the same race (Davis et al., 2007). Eight of these accessions exhibited high levels of resistance, and another 86 demonstrated intermediate resistance. Thomas et al. (2005) found 22 PIs with intermediate resistance to race $2 \mathrm{~W}$ (unspecified whether the race was 2 WUS or $2 \mathrm{WF}) P$. xanthii after screening $266 \mathrm{PI}$ accessions. More recently, Tetteh et al. (2010) reported that eight of $1654 \mathrm{PI}$ accessions and cultivars demonstrated high levels of resistance to race $2 \mathrm{~W}$. This race $2 \mathrm{~W}$ was resistant to 'Edisto 47' and susceptible to PI 414723, which did not allow differentiation into races $2 \mathrm{WUS}$ or $2 \mathrm{WF}$. There is no information previously published on resistance of Citrullus spp. to powdery mildew race $2 \mathrm{WF}$.

The most effective, least expensive for growers and safest method for controlling powdery mildew in crops is the use of resistant cultivars. The U.S. PI collection of Citrullus spp. contains lines collected from around the world, offering a wide diversity of germplasm for screening for powdery mildew resistance. The objective of this study was to evaluate the 2100 PI S1 lines produced from 820 U.S. PI Citrullus spp. accessions against the Bejing $P$. xanthii race $2 \mathrm{WF}$ isolate. We report here on $C$. lanatus $\mathrm{Pis}$ resistant to $P$. xanthii race $2 \mathrm{WF}$.

\section{Materials and Methods}

Germplasm. In 2005, the National Engineering Research Center for Vegetables (NERCV) imported 820 PI accessions of Citrullus spp. from the USDA, Southern Regional Plant Introduction Station at Griffin, GA. These accessions represent germplasm collected from 57 countries. The majority of the accessions were originally collected from Turkey (153), Zimbabwe (117), India (96), the former Yugoslavia (82), Spain (59), Zambia (48), P.R. China (23), and Syria (19). These PI accessions represent three species, $C$. lanatus var. lanatus (766), C. lanatus var. citroides (53), and C. colocynthis (1). One generation of controlled self-pollinations of these $820 \mathrm{PI}$ accessions were made to produce 2100 PI S1 lines to increase the likelihood of identifying recessively inherited resistance. The number 
of PI S1 lines from each original accession ranged from two to five. Each PI S1 line was named with the PI accession number followed by the line number $1,2,3,4$, or 5 . For lines in which few seeds were produced, seeds were bulked and labeled as the original PI numbers.

Pathogen. The powdery mildew isolate was collected from an infected watermelon field at NERCV in Beijing and was maintained on summer squash (Cucurbita pepo L.) 'ZaoQing'. Heavily sporulating leaves were placed in $0.02 \%$ Tween 20 and a sterile paint brush was used to release the conidia. The spore concentration was determined with a hemocytometer and adjusted to $2 \times 10^{5}$ conidia $/ \mathrm{mL}$ (Block and Reitsma, 2005). Inoculations with the spore suspensions were performed with a hand sprayer. Plants were sprayed until 3 to $4 \mathrm{~mL}$ of the spore suspension evenly coated the leaves of each seedling. Inocula were freshly prepared as needed and were used immediately after preparing.

To determine the race of the Beijing $P$. xanthii isolate, 13 melon differentials were inoculated: Iran H, 'PMR 5', 'Edisto 47', PI 414723, MR-1, and 'Nantais Oblong' supplied by Dr. M. Pitrat (INRA, Montfavet, France); and 'Védrantais', 'Top Mark', 'PMR 45', 'PMR 6', WMR29, PI 124111, and PI 124112 supplied by Dr. J.D. McCreight (USDA-ARS, Salinas, CA). Seedlings were rated for disease and race $2 \mathrm{WF}$ was the only race identified in all three experiments.

Seedling screening. The primary seedling screen of 2100 PI S1 lines was conducted in NERCV greenhouses during the summer of 2006. The 52 most resistant lines were retested in a secondary seedling screen conducted at the same location in the summer of 2007. Powdery mildew race verification and germplasm screenings were performed using the same experimental conditions. The melon differentials were included in each experiment.

The experiments were arranged in a randomized complete block designs with three replications. Fifteen seeds of each differential and 10 seeds of each PI S1 line were planted per replication. Additionally, 90 inoculated and uninoculated seedlings of the ZYMVsusceptible watermelon inbred line 98R were planted per replication as susceptible control plants. Inoculated checks served as verification of pathogen infection and uninoculated checks indicated no other diseases in the greenhouse that might confound symptom expression.

Seedlings were grown in $80 \times 80$-mm square pots $(600-\mathrm{mL}$ volume $)$ and placed on benches in a greenhouse set at 30 day $/ 25{ }^{\circ} \mathrm{C}$ night temperatures and $80 \% \pm 15 \%$ relative humidity. Seedlings were inoculated at $15 \mathrm{~d}$ after seeding, when most first true leaves were fully expanded.

Symptoms of powdery mildew infection on seedling watermelon manifested as white powdery growth on cotyledon or hypocotyl surfaces. Symptoms often started as small spots on the cotyledon surface and gradually covered the entire cotyledon and hypocotyl. Plant ratings were taken $15 \mathrm{~d}$ after inoculation. A 0 to 5 rating scale was used for evaluating seedlings, where $0=$ no evidence of infection,
$1=$ trace (less than 20\%) infection of cotyledons only, $2=$ low infection $(21 \%$ to $50 \%)$ of cotyledons or trace (less than 20\%) infection of hypocotyls, $3=$ moderate infection of cotyledons (51\% to $70 \%$ ) and low infection of hypocotyls $(21 \%$ to $50 \%), 4=$ severe infection (greater than $71 \%$ ) of cotyledons and hypocotyls, slight infection of leaves (less than 20\%), $5=$ whole plant infected and/or dead. Percent disease indices (PDI) were calculated using a formula developed by Wheeler (1969).

$$
\begin{aligned}
\text { PDI }= & \frac{\text { Sum of numerical disease ratings }}{\text { No. of plants observed }} \\
& \times \frac{100}{\text { Maximum disease rating value }}
\end{aligned}
$$

The lowest disease rating value was zero and the maximum disease rating value was five in the immature plant experiments. PI S1s with PDI 10.0 or less were classified as resistant, 10.1 to 40.0 as intermediately resistant, 40.1 to 60.0 as moderately susceptible, and 60.1 or greater as susceptible. All measurements were taken on individuals and averaged within replications and a grand mean developed over the three replications.

Mature plant screening. The 42 PI S1 lines demonstrating the strongest resistance (lowest PDI rating) in seedling experiments were tested for resistance at the mature plant stage. This experiment was conducted in NERCV plastic houses that did not have temperature-regulating capabilities during the fall of 2007 . Temperatures ranged from 23 to $40{ }^{\circ} \mathrm{C}$ (day) and 12 to $20^{\circ} \mathrm{C}$ (night). Humidity was maintained at $80 \% \pm 15 \%$ using a humidifier for optimal disease progression.

Seven to 10 plants (depending on germination rate) for each PI S1 line were planted in three replications. Seeds were sown directly in 2.5-inch plastic pots and placed on greenhouse benches until seedlings emerged. Inoculation was performed as mentioned previously. Seedlings were then moved and transplanted in the ground in a plastic house to investigate resistance using recommended fall cultural practices in China.

Symptoms of powdery mildew infection on mature watermelon manifested as white to gray powdery growth on the leaves or stem surfaces, which usually started as small spots on the leaf and gradually covered the entire leaf surface. As the disease progresses, this sporulation can be seen on the entire stem as well. Three weeks after transplanting, disease ratings were taken. Most plants were starting to set fruit at this time. The rating scale was expanded (zero to eight) for a more precise PDI on the mature plants, where $0=$ no symptom, $1=0 \%$ to $1 \%$ mycelium coverage on leaves or stem, $2=1 \%$ to $3 \%$ mycelium coverage, $3=3 \%$ to $5 \%$ mycelium coverage, $4=5 \%$ to $10 \%$ mycelium coverage, $5=10 \%$ to $20 \%$ mycelium coverage, $6=20 \%$ to $30 \%$ mycelium coverage, $7=30 \%$ to $40 \%$ mycelium coverage, $8=$ over $40 \%$ mycelium coverage with large necrotic areas. PDIs were calculated as described previously using a formula developed by Wheeler (1969).

Statistical analysis. Data were analyzed with PROC analysis of variance using SAS (Version 7; SAS Institute Inc., Cary, NC). The data were summarized as mean PDI of the replications for each study in Tables 1 and 2 .

\section{Results and Discussion}

Powdery mildew race $2 \mathrm{WF}$ confirmation. Using a set of melon differentials (Table 1), it is possible to identify seven races of $P$. xanthii (race $0,1,2 \mathrm{US}, 2 \mathrm{~F}, 3,4,5$ ) and two races of $G$. cichoracearum (McGrath and Thomas, 1996; Thomas et al., 1984). Susceptibility of Iran H, 'Vedrantais', 'Top Mark', and 'PMR 45' and resistance of 'PMR 5', 'PMR 6', 'Edisto 47', WMR 29, PI 414723, MR 1, PI 124112, and PI 124112 demonstrated that the $P$. xanthii race $2 \mathrm{WF}$ was the only powdery mildew race present during our studies (McCreight, 2006; Pitrat et al., 1998). Resistance of 'Edisto 47'

Table 1. Reactions of melon powdery mildew differentials to the Bejing race 2WF Podosphaera xanthii isolate. $^{\mathrm{z}}$

\begin{tabular}{lrc}
\hline Differential & PDI $^{\mathrm{y}} \pm \mathrm{SD}$ & Reaction \\
\hline Iran H & $90.0 \pm 3.9$ & Susceptible \\
Védrantais & $86.1 \pm 3.4$ & Susceptible \\
Top Mark & $85.9 \pm 1.3$ & Susceptible \\
PMR 45 & $80.7 \pm 3.8$ & Susceptible \\
PMR 5 & $0.0 \pm 0.0$ & Resistant \\
PMR 6 & $0.0 \pm 0.0$ & Resistant \\
Edisto 47 & $0.0 \pm 0.0$ & Resistant \\
WMR 29 & $0.0 \pm 0.0$ & Resistant \\
PI 414723 & $0.0 \pm 0.0$ & Resistant \\
MR-1 & $5.9 \pm 1.1$ & Resistant \\
PI 124111 & $4.4 \pm 0.5$ & Resistant \\
PI 124112 & $0.6 \pm 0.1$ & Resistant \\
Nantais Oblong & $87.7 \pm 2.0$ & Susceptible \\
\hline
\end{tabular}

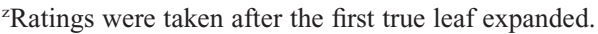

yPercent disease indices (PDI) were calculated using a formula developed by Wheeler (1969).

PDI $=\frac{\text { Sum of numerical disease ratings }}{\text { No. of plants observed }} \times \frac{100}{\text { Maximum disease rating value }}$

Melon lines with PDI 10.0 or less were classified as resistant, 10.1 to 40.0 as intermediate resistance, 40.1 to 60.0 as moderately susceptible, 60.1 or greater as susceptible. All measurements were taken on individuals and averaged within replications and then the three replications were averaged. Fifteen seeds of each differential were planted in each of three replications in a randomized complete block design. All surviving plants were evaluated. 
Table 2. Ranking of the 42 most resistant watermelon lines using percent disease indices for race $2 \mathrm{WF}$ Podosphaera xanthii resistance. ${ }^{2}$

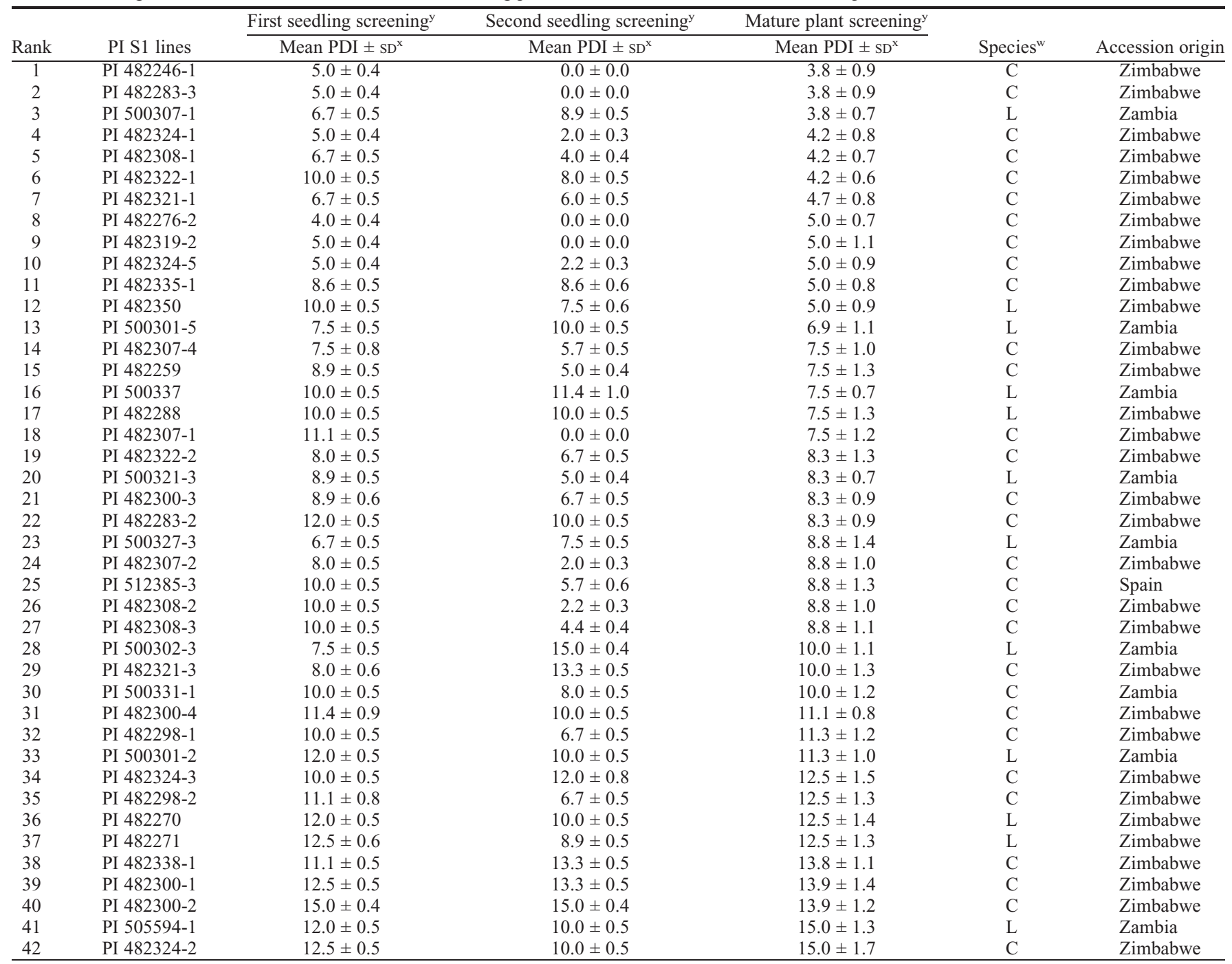

${ }^{2}$ Rankings were based on the mature plant screening experiments of Citrullus species PI S1 lines. Plants ranked from 1 to 30 demonstrated resistance; plants ranked from 31 to 42 demonstrated intermediate resistance.

${ }^{y}$ Resistance of the PI S1 lines to race 2WF P. xanthii determined using three disease severity ratings. The first seedling rating, consisted of 2100 PI S1 lines. Ten seeds of each PI S1 line were planted in each of three replications in a randomized complete block design. Based on the results of the initial screening, 52 PI S1 lines were selected and reevaluated again at the seedling stage. The most resistant 42 PI S1 lines were further evaluated at the mature plant stage. Seven to 10 plants in each of three nonrandom replications from each selected PI S1 lines were planted.

${ }^{x} \mathrm{PI}$ S1 lines were classified as resistant, intermediate resistant, moderately susceptible, and susceptible according to the percent disease indices (PDI) given by Wheeler (1969).

PDI $=\frac{\text { Sum of numerical disease ratings }}{\text { No. of plants observed }} \times \frac{100}{\text { Maximum disease rating value }}$

PI S1 lines with PDI 10.0 or less were classed as resistant, 10.1 to 40.0 as intermediate resistance, 40.1 to 60.0 as moderately susceptible, 60.1 or greater as susceptible. All measurements were taken on individuals and averaged within replication and then the three replications were averaged.

${ }^{\mathrm{w}} \mathrm{L}=$ Citrullus lanatus var. lanatus $; \mathrm{C}=$ C. lanatus var. citroides.

and PI 414723 distinguished this isolate as race $2 \mathrm{WF}$ and not race $2 \mathrm{WUS}$. Previous studies demonstrated that race $1 \mathrm{~W}$ and race 2W affect watermelon (Davis et al., 2007; Tetteh et al., 2010). This study confirmed that race $2 \mathrm{WF}$ (Wang et al., 2006) can also infect watermelon.

Germplasm screening. To avoid escapes, PI S1 lines that appeared resistant in the first seedling test were retested again at the seedling stage. Ten PI S1 lines were susceptible in the retest. The most resistant (42) lines in the second screen were rescreened at the mature plant stage using normal fall production methods. Conditions for powdery mildew disease were favorable during the mature plant experiment, as noted by the prevalence of the disease on other cucurbit crops at the same research facility $(70 \%$ of cucumber and $80 \%$ of squash plants exhibited signs of infection) (data not shown).

Data from the mature stage screening and the two seedling stage experiments were in general agreement (Table 2). Correlation analysis of PDI ratings by line across all three experiments was significant and positively correlated $(r=0.70 ; P<0.0001)$. Likewise, significant and positive correlations were observed between the first seedling screening and the mature stage experiment $(r=0.80$; $P<0.0001)$ and between the second seedling screening and the mature stage experiment $(r=0.74 ; P<0.0001)$. These data indicate repeatable experimental results and a reasonable amount of trait stability within the PI S1 lines.

When data from all three experiments were combined and all PI S1 lines ranked for resistance, no line was immune. The majority $(92 \%)$ had PDI 60.1 or greater and was classified as susceptible. Only $0.02 \%$ (42 PI S1 lines representing 27 PI lines) had PDI 15.00 or less in the seedling experiments. These lines demonstrated resistance or intermediate resistance in all three experiments; in Table 2, plants were ranked by their mature PDI ratings. The line with the lowest mature plant PDI average (most resistant) was ranked as one; the line with the highest PDI was 
ranked 42. These 42 PI S1 lines have commercially useful resistance to the race $2 \mathrm{WF}$ pathotype. PI lines from which the most resistant (mature PDI less than 6) PI S1 lines originated were PI 482246, PI 482283, PI 500307, PI 482324, PI 482308, PI 482322, PI 482321, PI 482276, PI 482319, PI 482335, and PI 482350.

The 42 PI S1 lines tested in the mature plant experiment represented $27 \mathrm{PI}$ accessions; 18 PI accessions were collected in Zimbabwe, eight originated from Zambia, and one accession came from Spain (Table 2). Because watermelon originated in Africa, it is not surprising that most of the resistance came from African accessions. This finding is consistent with data from Davis et al. (2007) and Tetteh et al. (2010) for race $1 \mathrm{~W}$ and race $2 \mathrm{~W}$. Twelve C. lanatus var. lanatus and 30 C. lanatus var. citroides demonstrated resistance in our study. Considering 766 C. lanatus and only $53 C$. lanatus var. citroides families were initially screened, this suggests that $C$. lanatus var. citroides may be a good source of additional powdery mildew-resistant genes.

The 30 most resistant PI S1 lines (mature PDI 10 or less) were developed from 22 PI lines. When these 22 resistant lines were compared with lines with resistance for race 1W (Davis et al., 2007), there were seven lines with resistance, or intermediate resistance, to both races (PI 482259, PI 482288, PI 482307, PI 482308, PI 500301, PI 500331, and PI 500337). PI 482259, PI 482283, PI 482307, PI 482319, and PI 500331 demonstrated resistance, or intermediate resistance, to powdery mildew race $2 \mathrm{~W}$ (Tetteh et al., 2010) and race 2WF. PI 482283, previously rated as susceptible to $P$. xanthii race $2 \mathrm{~W}$ (Thomas et al., 2005), was one of the most resistant lines in our tests (Table 2). PI 482259, PI 482307, and PI 500331 exhibited resistance, or intermediate resistance, to all three races of watermelon powdery mildew. Race $1 \mathrm{~W}$-resistant line PI 525088 and race 2W-resistant line PI 189225 did not show resistance to race $2 \mathrm{WF}$.

Heterogeneity of resistance within PI lines. Because many USDA PI accessions were increased by open pollination, or by sib pollination, there is often heterogeneity for disease resistance within these accessions (Davis et al., 2007). This is the likely reason why some PI S1 lines demonstrated different resistance levels. For example, of five PI S1 lines of PI 482324, two of them, PI 482324-1 and PI 482324-5, were highly resistant (PDI below 6.0), whereas PI 482324-2 and PI 482324-3 demonstrated intermediate resistance (PDI were 12.5 and 15.0), and PI 482324-4 was susceptible (PDI 55.0). Within $\approx 50 \%$ of the selfed PI S1 lines, there was phenotypic variability. This variability reduced disease resistance ranking for these accessions.

Independent genetic control of resistance in cotyledons and true leaves was reported in melon (McCreight, 2003). Additionally, Davis et al. (2007) and Tetteh et al. (2010) reported that in watermelon, resistance in the hypocotyls, leaf, and stem was under different genetic control. The race $2 \mathrm{WF}$ infection in this study was visually more uniform than with previously reported races. Symptoms appeared on cotyledons before noticeable symptoms appeared on hypocotyl, stem, or leaf tissue. The cotyledon always demonstrated more susceptibility than the other plant tissues. In this article, the evaluation criteria included hypocotyls, leaves, and stems, and plants were screened at the seedling and mature stages. The mature stage experiment was performed under normal fall production practices. We felt the more natural growing conditions would yield the most accurate representation of natural powdery mildew disease; therefore, the mature plant ratings were used to rank the most resistant lines. The PI lines that generated the PI S1 lines with the highest resistance were: PI 482246, PI 482283, PI 500307, PI 482324, PI 482308, PI 482322, PI 482321, PI 482276, PI 482319, PI 482335, and PI 482350. This is the first report showing resistance to race $2 \mathrm{WF}$ in watermelon, and our results support other reports that powdery mildew resistance can be identified in watermelon germplasm collections (Davis et al., 2007; Tetteh et al., 2010; Thomas et al., 2005).

\section{Literature Cited}

Block, C.C. and K.R. Reitsma. 2005. Powdery mildew resistance in the U.S. National plant germplasm system cucumber collection. HortScience 40:416-420.

Davis, A.R., B.D. Bruton, S.D. Pair, and C.E. Thomas. 2001. Powdery mildew: An emerging disease of watermelon in the United States. Cucurbit Genet. Coop. 24:42-48.

Davis, A.R., A. Levi, A. Tetteh, T.C. Wehner, V.M. Russo, and M. Pitrat. 2007. Evaluation of watermelon and related species for resistance to race $1 \mathrm{~W}$ powdery mildew. J. Amer. Soc. Hort. Sci. 132:790-795.

Davis, A.R., A. Levi, T.C. Wehner, and M. Pitrat. 2006. PI 525088-pmr, a melon race 1 powdery mildew-resistant watermelon line. HortScience 47:1527-1528.

FAO of the United Nations. 2011. Food and Agricultural commodities production. 10 May 2011. $<$ http://faostat.fao.org/site/339/default.aspx>.

Feng, D.X. 1996. The recent progress in resistance powdery mildew breeding of cucurbitaceous. China Vegetable 7:55-59 [in Chinese with English abstract].
Hosoya, K., K. Narisawa, M. Pitrat, and H. Ezura. 1999. Race identification in powdery mildew (Sphaerotheca fuliginea) on melon (Cucumis melo) in Japan. Plant Breed. 118:259-262.

Kristková, E. and A. Lebeda. 2000. Citrullus lanatus - A potential host of powdery mildew in the Czech Republic. Cucurbit Genet. Coop. Rpt. 23:46-48.

Lebeda, A., E. Kristková, B. Sedlakova, J.D. McCreight, and M.D. Coffey. 2008. New concept for determination and denomination of pathotypes and races of cucurbit powdery mildew, p. 125-134. In: Pitrat, M. (ed.). Proc. Cucurbitaceae 2008. INRA, Avignon, France.

Lebeda, A., M.T. McGrath, and B. Sedláková. 2010. Fungicide resistance in cucurbit powdery mildew fungi, p. 221-246. In: Carisse, O. (ed.). Fungicides. InTech-Open Access Publisher. 10 May 2011. <http://www.intechopen.com/ books/show/title/fungicides $>$.

McCreight, J.D. 2003. Genes for resistance to powdery mildew races 1 and 2U.S. in melon PI 313970. HortScience 38:591-594.

McCreight, J.D. 2006. Melon powdery mildew interactions reveal variation in melon cultigens and Podosphaera xanthii races 1 and 2. J. Amer. Soc. Hort. Sci. 131:59-65.

McCreight, J.D., M. Pitrat, C.E. Thomas, A.N. Kishaba, and G.W. Bohn. 1987. Powdery mildew resistance genes in muskmelon. J. Amer. Soc. Hort. Sci. 112:156-160.

McGrath, M.T. 2001. Fungicide resistance in cucurbit powdery mildew: Experiences and challenges. Plant Dis. 85:236-245.

McGrath, M.T. and C.E. Thomas. 1996. Powdery mildew, p. 28-30. In: Zitter, T.A., D.L. Hopkins, and C.E. Thomas (eds.). Compendium of cucurbit diseases. APS Press, St. Paul, MN.

Pitrat, M., C. Dogimont, and M. Bardin. 1998. Resistance to fungal diseases of foliage in melon, p. 167-173. In: McCreight, J.D. (ed.). Cucurbitaceae '98. ASHS Press, Alexandria, VA.

Shishkoff, N. and M.T. McGrath. 2001. Distribution of cucurbit powdery mildew races 1 and 2 on watermelon and muskmelon. Phytopathology 91:S197.

Tetteh, A.Y., T.C. Wehner, and A.R. Davis. 2010. Identifying resistance to powdery mildew race $2 \mathrm{~W}$ in the USDA-ARS watermelon germplasm collection. Crop Sci. 50:933-939.

Thomas, C.E., E. Kishaba, J.D. McCreight, and P.E. Nugent. 1984. The importance of monitoring races of powdery mildew on muskmelon. Cucurbit Genet. Coop. Rep. 7:58-59.

Thomas, C.E., A. Levi, and E. Caniglia. 2005. Evaluation of U.S. plant introductions of watermelon for resistance to powdery mildew. HortScience 40:154-156.

Wang, J., G.Y. Gong, S.G. Guo, Q. Wang, and Y. Xu. 2006. Identification of physiological races of powdery mildew on cucurbits in Beijing. China Vegetables 8:7-9 [in Chinese with English abstract].

Wheeler, B.E.J. 1969. An introduction to plant diseases. John Wiley and Sons Ltd., London, UK, p. 301. 